Article

\title{
Alendronate Release from UHMWPE-Based Biomaterials in Relation to Particle Size of the GUR Powder for Manufacturing
}

\author{
Michael Seidenstuecker ${ }^{1, *(D)}$, Julia Weber ${ }^{1,2}$, Sergio H. Latorre ${ }^{1}$, Brigitte Straub ${ }^{2}$, \\ Ulrich Matthes $^{3}$, Christian Friedrich ${ }^{3}$, Hermann O. Mayr ${ }^{1}$ and Anke Bernstein ${ }^{1}$ \\ 1 G.E.R.N. Tissue Replacement, Regeneration \& Neogenesis, Department of Orthopedics and Trauma Surgery, \\ Medical Center-Albert-Ludwigs-University of Freiburg, Faculty of Medicine, Albert-Ludwigs-University of \\ Freiburg, Hugstetter Str. 55, 79106 Freiburg, Germany; juli-weber@hotmail.de (J.W.); \\ sergio.latorre@uniklinik-freiburg.de (S.H.L.); hermann.mayr@uniklinik-freiburg.de (H.O.M.); \\ anke.bernstein@uniklinik-freiburg.de (A.B.) \\ 2 Faculty Mechanical and Medical Engineering, Furtwangen University, Robert-Gerwig-Platz 1, \\ 78120 Furtwangen, Germany; sbr@hs-furtwangen.de \\ 3 Freiburg Materials Research Center (FMF) and Institute for Macromolecular Chemistry of the \\ Albert-Ludwigs University Freiburg, Stefan-Meier-Str. 21, D-79104 Freiburg, Germany; \\ ulrich.matthes@fmf.uni-freiburg.de (U.M.); christian.friedrich@fmf.uni-freiburg.de (C.F.) \\ * Correspondence: michael.seidenstuecker@uniklinik-freiburg.de; Tel.: +49-761-270-26104
}

Received: 21 May 2019; Accepted: 4 June 2019; Published: 6 June 2019

check for updates

\begin{abstract}
Ultra-high molecular weight polyethylene (UHMWPE) is widely used in endoprosthetics and has been the subject of countless studies. This project investigates the dependence of alendronate (AL) release on the molecular weight of the UHMWPE used (GUR1020 and GUR1050). A $0.5 \mathrm{wt} \%$ AL was added to the UHMWPE during the production of the moldings. In addition to the 14-day release tests, biocompatibility tests such as live dead assay, cell proliferation assay (WST) and Lactate dehydrogenase test (LDH) with MG-63 cells as well as a tensile test according to DIN EN ISO 527 were carried out. The released AL concentration was determined by HPLC. A continuous release of the AL was observed over the entire period of 2 weeks. In addition, a correlation between molar mass and AL release was demonstrated. The GUR1020 showed a release four times higher than the GUR1050. Both materials have no negative influence on the proliferation of MG-63 cells. This was also confirmed in the live/dead assay by the increase in cell count. No cytotoxicity was detected in the $\mathrm{LDH}$ test. The addition of $0.5 \mathrm{wt} \%$ AL increased the elongation at break for GUR1020 by $23 \%$ and for GUR1050 by $49 \%$. It was demonstrated that the choice of UHMWPE has an influence on the release of AL. The particle size in particular has a strong influence on the release behavior.
\end{abstract}

Keywords: UHMWPE; GUR1020; GUR1050; alendronate; osteoporosis; aseptic loosening; drug release; HPLC

\section{Introduction}

The fact that we are living so much longer means that the percentage of people eventually needing an artificial joint will also rise dramatically. In 2016, there were 187,319 initial implantations of total knee replacements (TKRs), and 24,940 revision surgeries for TKRs in Germany [1]. The annual operative frequency of initial endoprosthetic hip and knee surgery among Germans has remained stable and not risen since 2007. Initial hip interventions in the over-70 age group amounted to $1.1 \%$ (in 2007 and 2014), and initial knee interventions $0.7 \%$ (2007) and $0.6 \%$ (2014). The operative frequency in the entire German population was $0.26 \%$ in 2014 (hips) and $0.19 \%$ (knees) [2]. However, $6.5 \%$ of the TKR had 
to be replaced within the first two postoperative years. Of the revised interventions, $55 \%$ were due to aseptic loosening [3], a process caused by minute polyethylene particles abraded from the inlay made of ultra-high molecular weight polyethylene (UHMWPE) in knee endoprosthesis [4]. Despite good sliding characteristics, wear particles arise that are phagocytized by macrophages. In reacting to these non-decomposable particles, the macrophages discharge inflammatory mediators that increase osteoclastic activity [5]. The central mechanism of abrasion particle-induced osteolysis is elevated bone resorption through osteoclasts. The therapeutic targeting of osteoclast function is a logical means of treating or at least minimizing the occurrence of aseptic loosening after total joint replacement. The therapy for an endoprosthesis loosened by periprosthetic osteolysis usually entails removal of the old and implantation of a new endoprosthesis. Such surgical revisions are associated with a high degree of morbidity and impaired function. More recent approaches to osteolysis suppression focus on understanding and manipulating osteolysis at the molecular level through pharmacological intervention [6]. Potential biological treatments involve reagents such as bisphosphonate, statins, and antagonists for the Receptor Activator of Nuclear Factor Kappa B Ligand (RANKL), considered a signal transducer of osteoclasts onto osteoblasts. Various studies have demonstrated that nitrogenous bisphosphonates such as zolendronate can inhibit abrasion-induced osteolysis and lead to increased peri-implant bone density [7,8]. Alendronate belongs to the group of bisphosphonates and is already being applied in medical therapy and prophylactically for osteoporosis [9]. Bone structure is made denser by the consistent delivery of alendronate, making the bone less fracture prone $[10,11]$. These effects rely on inhibiting osteoclastic activity. Figure 1 illustrates the chemical structure of alendronate sodium $\left(\mathrm{C}_{4} \mathrm{H}_{12} \mathrm{NNaO}_{7} \mathrm{P}_{2} \cdot 3 \mathrm{H}_{2} \mathrm{O}\right)$.

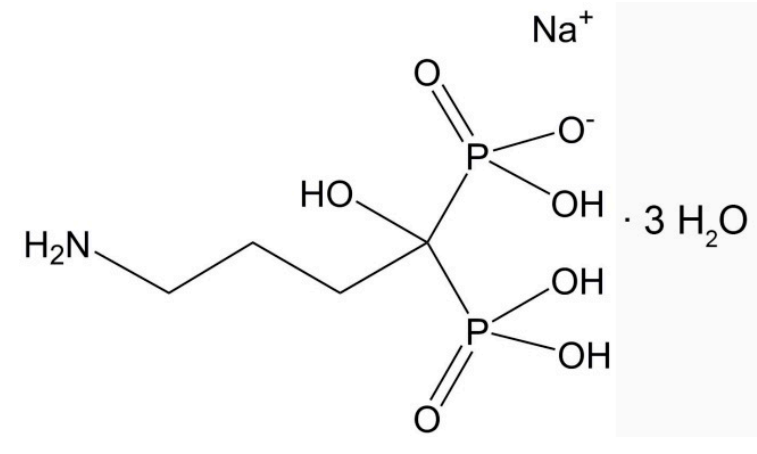

Figure 1. Alendronate sodium.

The type of polyethylene (PE) usually employed to manufacture prostheses is UHMWPE [12]. It triggers fewer abrasion particles than PE with a lower molar mass, as well as greater stability and better gliding qualities. In working on this project, the focus was on the polyethylenes GUR1020 and GUR1050 [13]. The materials used in our experiments (GUR1020 und GUR1050) are medical substances and categorized as UHMWPE. These materials have been administered around the world for orthopedic purposes (e.g., joint replacements). Their only differences lie in their molecular weight [13]: GUR1020 $\left(3.5 \times 10^{6} \mathrm{~g} / \mathrm{mol}\right)$ and GUR1050 $\left(5.5-6 \cdot 10^{6} \mathrm{~g} / \mathrm{mol}\right)$.

AL was integrated into UHMWPE as an active ingredient. As such, the active ingredient's systemic concentration must be kept as low as possible to prevent potential side effects, something only possible when it is applied locally onto the target cells. The active ingredient AL must be integrated homogeneously within the polymer matrix so that the concentration can be achieved that is necessary to prevent the onset of particle-induced periprosthetic osteolysis prior to OA. This concentration is maintained during the endoprosthesis' lifetime by the particles released during the abrasion process and the associated release of the active substance.

In the release experiments described in the literature of alendronate from UHMWPE [14-16], abrasion particles were produced from which AL was later released [14,16], and AL release attempts 
were made from GUR1020 [15]. However, no attempt has been made until now to investigate the relationship between release behavior and the particle size. In this study, the influence of the particle size of different UHMWPEs on the release behavior of AL was investigated. The biocompatibility of GUR1020/1050 and alendronate composites was also evaluated, so that alendronate can be eventually added to the prosthesis material during the manufacturing process.

\section{Materials and Methods}

\subsection{Reagents and Materials}

GUR1020 und GUR1050 were obtained from Ticona/Celanese (Dallas, USA). Alendronate (AL) sodium, o-Phtadialdehyde (OPA), 2-Mercaptoethanol (2ME) and Tetrabutylammoniumperchlorate (TBA) were purchased from Sigma Aldrich (Darmstadt, Germany). Sodium hydrogen phosphate, di-sodium hydrogen phosphate and Acetonitril (ACN) were from Carl Roth (Karlsruhe, Germany). All these chemicals met HLPC standards.

\subsection{Sample Preparation}

Sample preparation was similar to Qu et al. [16], but with a different temperature control to keep the AL from disintegrating. A GUR-alendronate batch containing $0.5 \mathrm{wt} \%$ alendronate was prepared. To do this, the AL was dissolved in 1:5 ethanol:double-distilled water and then mixed with GUR-powder (1020 or 1050). The resultant dispersion was then dried at $35^{\circ} \mathrm{C}$ in a vacuum drying oven (Memmert, Schwabach, Germany). A total of $1.55 \mathrm{~g}$ of each sample was pressed into shape $(60 \times 13 \times 2 \mathrm{~mm})$ at $140^{\circ} \mathrm{C}$ with $60 \mathrm{bar}$, with a slab press type P $200 \mathrm{P}$ with vacuum function (Dr. Collin $\mathrm{GmbH}$, Ebersberg, Germany) (see Figure 2). There were also samples from pure GUR (1020/1050) without adding any chemical agents produced.

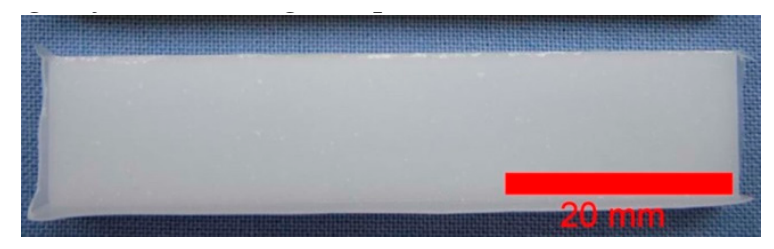

Figure 2. GUR molds after pressing, red bar $=20 \mathrm{~mm}$.

The resultant molds (cf. Figure 2) were cut into sections measuring $10 \times 13 \times 2 \mathrm{~mm}$ for the release experiments. For the cell experiments, cylinders measuring ø $10 \mathrm{~mm}$ were die cut out of the molds. These round test specimens were better suited for cell-culture slides, whereas the angled ones are more appropriate for release experiments thanks to having a larger surface.

\subsection{Characterization of the GUR and the Molds}

\subsubsection{Particle Size}

The particle size was determined using a Morphologi G3 (Malvern Panalytical, Malvern, UK) particle measuring device. A defined volume was introduced into the atomizer of the Morphologi G3 with a spatula and atomized at 2 bar for $30 \mathrm{~ms}$ on the slide. Then at least 3000 particles per GUR with $5 \times$ magnification were recorded and measured. The measurements were repeated 3 times.

\subsubsection{Weight and Dimensions}

After sawing or punching out the GUR bodies, the exact width and thickness were determined using an electronic sliding calliper (Burg-Wächter, Wetter, Germany) and the weight of at least 10 samples per GUR/composite was determined using a Sartorius precision balance. 


\subsubsection{Surface Roughness}

A total of 6 samples from each batch (GUR1020, GUR1050, GUR1020AL, GUR1050AL) were examined under a 3D laser-scanning microscope (3DLSM) (VK-X210, Keyence, Osaka, Japan), at room temperature and at $1000 \times$ magnification, concentrating on their surface structure. A surface measuring $64,000 \mu \mathrm{m}^{2}$ was examined to assess each sample's surface roughness, and multiple measurements were taken at five different positions on each sample. The arithmetical mean height $\mathrm{S}_{\mathrm{a}}$ of each sample was determined corresponding to JIS B0601:2001 (ISO 4287:1997).

\subsubsection{Tensile Testing}

The tensile tests were performed on a universal testing machine Z005 (Zwick/Roell, Ulm, Germany) according to DIN EN ISO 527 with a 5-kN load cell. The specimens were produced as described previously and die cut in Form 5A for the tensile tests. Following the DIN norm, first the young's module at $1 \mathrm{~mm} / \mathrm{min}$ velocity and then the tensile strength until total failure at a velocity of $50 \mathrm{~mm} / \mathrm{min}$ was tested. A total of 6 samples of each GUR and composite specimen were assessed.

\subsubsection{Crystallinity}

The crystallinity of specimens with and without AL was assessed via differential scanning calorimetry (DSC). These DSC measurements were taken on a DSC 204F1 Phoenix (Netzsch Gerätebau $\mathrm{GmbH}$, Selb, Germany) within a $20-200{ }^{\circ} \mathrm{C}$ temperature range with a heating-up rate or cooling-down rate of $10 \mathrm{~K} / \mathrm{min}$ under a nitrogen atmosphere. Four samples of each GUR and composite were analyzed.

The percent crystallinity was measured in dry N2 according to ASTM D3418-03. The enthalpy of fusion $\left(\mathrm{H}_{\mathrm{f}}\right)$ was calculated by integrating the DSC endotherm from the second heating curve. According to the UHMWPE Biomaterials Handbook [17], the $\mathrm{H}_{\mathrm{f}}$ of $100 \%$ crystalline UHMWPE equaled $288 \mathrm{~J} / \mathrm{g}$. The percent crystallinity was calculated by dividing the $\mathrm{H}_{\mathrm{f}}$ of the sample by $288 \mathrm{~J} / \mathrm{g}$ and multiplying by 100 .

\subsection{Release Experiments}

Each mold for the release experiments $(\mathrm{N}=10)$ was immersed in $2 \mathrm{~mL}$ twice-distilled water and weighed down with glass rings (outer diameter $=8 \mathrm{~mm}$, inner diameter $=6 \mathrm{~mm}$ ) to prevent them from floating to the surface. The release experiments were carried out over 14 days at $37^{\circ} \mathrm{C}$. The specimens were brought into motion with a shaking device (Rocker 2D basic, IKA, Staufen, Germany). The fluids were removed entirely at specific timepoints $(1,2,3,6,8$ und 14 days) and replaced with fresh double-distilled water (arium pro, Sartorius). These fluid specimens were then deep-frozen at $-20{ }^{\circ} \mathrm{C}$ for later experimental use. The release behavior of 10 samples from each specimen was examined in triplicate.

\subsection{HPLC}

\subsubsection{Equipment}

HPLC analysis took place with a HPLC System (Shimadzu, Kyoto, Japan) consisting of 2 Nexera XR LC-20AD pumps and a SIC-30AC autosampler, CTO 20 AC column oven, DGU-20A5R Degasser, SPD-M20A PDA detector, RF 20A fluorescence detector and a CBM-20A controller. A Hamilton PRP-1 column $(5 \mu \mathrm{m}, 150 \mathrm{~mm} \times 4.1 \mathrm{~mm})$ was used to take HPLC measurements.

\subsubsection{Buffer Preparation}

The phosphate buffer $\mathrm{pH} 9.6$ was produced after Sorensen [18]. The $3 \mathrm{wt} \%$ TBA was added; the $\mathrm{pH}$ value was tested and, if necessary, readjusted with phosphoric acid to $\mathrm{pH}$ 9.6. The buffer solution was filtered through a polycarbonate membrane with a pore size of $0.4 \mu \mathrm{m}$ under a partial vacuum at 500 mbar prior to being employed at the HPLC. 


\subsubsection{Derivatization Solution}

A working solution according to Al Deeb et al. [19] was used. Therefore, $50 \mathrm{mg}$ OPA was dissolved in $5 \mathrm{~mL} 0.05 \mathrm{M} \mathrm{NaOH}$, then $250 \mu \mathrm{L} 2 \mathrm{ME}$ was added and the solution was topped up with $0.05 \mathrm{M}$ $\mathrm{NaOH}$ to $50 \mathrm{~mL}$. A fresh batch of this solution was made every day.

\subsubsection{Chromatographic Settings}

The chromatographic separations and the subsequent quantifications were performed at room temperature using a reversed-phase HPLC column. The chromatogram was documented using the fluorescence detector (excitation: $333 \mathrm{~nm}$, emission $455 \mathrm{~nm}$ ). An isocratic solvent system consisting of a mixture of ACN/phosphate buffer pH 9.6 (15:85) with $3 \mathrm{wt} \%$ TBA according to Al Deeb et al [19] at a flow rate of $1 \mathrm{~mL} / \mathrm{min}$ was used.

\subsubsection{Calibration Curve}

A stock solution containing $1 \mathrm{mg} / \mathrm{mL}$ alendronate in $0.05 \mathrm{M} \mathrm{NaOH}$ was prepared. Aliquots were extracted from the stock solution for calibration, then transferred to HPLC vials, mixed $60 \mu \mathrm{L} \mathrm{OPA} / 2 \mathrm{ME}$ into each one, and filled up to $1 \mathrm{~mL}$ with $0.05 \mathrm{M} \mathrm{NaOH}$. After allowing $60 \mathrm{~min}$ reaction time, the specimens were analyzed via HPLC. The various concentrations $(10-200 \mu \mathrm{g} / \mathrm{mL})$ were produced fresh daily for the calibration.

\subsubsection{Preparing the Specimens}

The samples obtained from the release experiments were mixed with $60 \mu \mathrm{L}$ OPA/2ME and filled up to $1 \mathrm{~mL}$, analogous to 2.4.5. These samples were then analyzed $60 \mathrm{~min}$ later via HPLC and a fluorescence detector (333 nm excitation, $455 \mathrm{~nm}$ emission).

\subsection{Biocompatibility Investigations}

The cell-culture experiments were performed with an MG-63 cell line (ATCC CRL-1427). To do this, the die-cut GUR specimens were first sterilized in an autoclave (Varioklav 135T) (HP Medizintechnik $\mathrm{GmbH}$, Oberschleißheim, Germany) and then fixed onto the base of a 24-well plate with Futar D (Kettenbach GmbH \& Co. KG, Eschenburg, Germany), a dental adhesive based on vinylpolysiloxane. A total of 5000 MG-63 cells were seeded onto each specimen and completely covered with medium, and then incubated in an incubator (Galaxy 170R, New Brunswick, Canada) for a specific time period. All biocompatibility tests involved at least three specimen GURs or composites at each time point, and each test was repeated three times. The specimens were examined microscopically under the BX51fluorescence microscope (Olympus, Tokyo, Japan) and BX51 light microscope (Olympus, Tokyo, Japan) with Software Stream Motion. In all the following investigations, at least three samples of each GUR or composite specimen was tested at each timepoint, and at least 5 different positions on each of those samples were examined microscopically at $5 \times$ and $10 \times$ magnification. The internal light source of the BX 51 was used for light microscopy and an external light source with $\lambda=490 \mathrm{~nm}$ was used for fluorescence microscopy. The filter we used enabled us to observe red and green fluorescing cells simultaneously. The cell count was performed by hand using the Photoshop CS6 counting software (Adobe, San José, USA). The mean values of cell count were calculated and then converted into cell count values per $\mathrm{mm}^{2}$.

\subsubsection{Live/Dead Assay}

This staining procedure was performed after $24 \mathrm{~h}, 48 \mathrm{~h}$ and $72 \mathrm{~h}$ with "Live/Dead Cell Straining Kit II" from PromoKine. Calcein stains live cells green (Ex/Em $495 \mathrm{~nm} / 515 \mathrm{~nm}$ ), while EthD-III stains the dead ones red (Ex/Em $530 \mathrm{~nm} / 635 \mathrm{~nm})$. Microscopy was performed as stated previously. 


\subsubsection{Cell Proliferation Test (WST)}

For this test "Cell Proliferation Reagent WST-1" from Roche was used, measuring after 1, 2, 3, 7 and 10 days at $\lambda=450 \mathrm{~nm}$ and $\lambda=600 \mathrm{~nm}$ as a reference in a photometer (SPECTROstar ${ }^{\text {Nano }}$, BMG Labtech $\mathrm{GmbH}$ ). The WST reagent was added at a ratio of 1:10 to the DMEM-F12 medium (without red phenol) and incubated for $2 \mathrm{~h}$ at $37^{\circ} \mathrm{C}, 5 \% \mathrm{CO}_{2}$. From each well, $100 \mu \mathrm{L}$ of the liquid was then pipetted into a new $96-$ well plate in triplicate.

\subsubsection{LDH Test}

A total of 25000 cells was seeded onto each specimen. This experiment was conducted with Roches "Cytotoxicity Detection Kit (LDH)". Measurements were taken after 1, 2 and 3 days at $\lambda=490 \mathrm{~nm}$ in a photometer. In so doing, we added $100 \mu \mathrm{L}$ freshly prepared LDH solution to each $100 \mu \mathrm{L}$ of the medium used (phenol red free, 1\% Pen Strep, 1\% FBS Superior). These mixtures then had to undergo incubation for at least $30 \mathrm{~min}$ in the dark and were then measured photometrically.

\subsection{Statistical Analysis}

Data were expressed as mean \pm standard deviation of the mean and analyzed by one-way analysis of variance (ANOVA). The level of statistical significance was set at $p<0.05$. For statistical calculations, Origin 2018 Professional SR1 (OriginLab, Northampton, USA) was used.

\section{Results}

\subsection{GUR and Specimen Characterization}

\subsubsection{Particle Size}

Particle size measurements showed different size distributions for the different GUR types. GUR1050 showed a larger proportion of small particles between 1 and $10 \mu \mathrm{m}$ with $57 \%$, whereas GUR1020 with $36.5 \%$ had a significantly smaller value for this particle size class. Looking at the small particle sizes of 1-30 $\mu \mathrm{m}$ together, the GUR1050 with $83.2 \%$ had a significantly higher proportion of small particles than the GUR1020 with $69.1 \%$. Table 1 shows the comparison of the different particle size classes for the two GUR types. The mean particle diameter for GUR1020 was $54.3 \pm 52.5 \mu \mathrm{m}$ and $36.9 \pm 38.3 \mu \mathrm{m}$ for GUR1050.

Table 1. Particle size distribution of the different GUR types [ $\mathrm{N}=3000]$.

\begin{tabular}{ccc}
\hline \multirow{2}{*}{ Particle Size Classes $[\mu \mathrm{m}]$} & \multicolumn{2}{c}{ Percentage [\%] } \\
\cline { 2 - 3 } & GUR1020 & GUR1050 \\
\hline $0.1-10$ & 36.52 & 56.76 \\
$11-30$ & 32.61 & 26.45 \\
$31-50$ & 6.78 & 4.66 \\
$51-70$ & 8.06 & 3.25 \\
$71-90$ & 5.65 & 1.13 \\
$91-110$ & 2.41 & 1.55 \\
$111-130$ & 2.33 & 1.45 \\
$131-150$ & 1.81 & 1.37 \\
$151-170$ & 1.95 & 1.55 \\
$171-190$ & 0.82 & 1.06 \\
$191-210$ & 0.68 & 0.37 \\
$211-230$ & 0.15 & 0.25 \\
$231-250$ & 0.15 & 0.06 \\
$251-270$ & 0.08 & 0 \\
$271-290$ & 0 & 0.06 \\
\hline
\end{tabular}




\subsubsection{Weights and Dimensions}

The specimens were on average $9.51 \pm 0.05 \mathrm{~mm}$ in width, $12.80 \pm 0.15 \mathrm{~mm}$ in length, $2.09 \pm 0.06 \mathrm{~mm}$ in height and weighed $0.24 \pm 0.01 \mathrm{~g}$. Table 2 shows the dimensions and weights of the specimens we used in our release experiments. Specimens GUR1020AL and GUR1050AL contained 0.5 wt\% AL.

Table 2. Dimensions and Weights of Specimens for Release Testing [ $\mathrm{N}=10]$.

\begin{tabular}{lcccc}
\hline \multicolumn{1}{c}{ Specimen } & Width $[\mathrm{mm}]$ & Length $[\mathrm{mm}]$ & Height $[\mathrm{mm}]$ & Weight $[\mathrm{g}]$ \\
\hline GUR1020 & $9.57 \pm 0.28$ & $12.72 \pm 0.03$ & $2.12 \pm 0.02$ & $0.25 \pm 0.01$ \\
GUR1050 & $9.49 \pm 0.31$ & $12.71 \pm 0.02$ & $2.11 \pm 0.01$ & $0.24 \pm 0.01$ \\
GUR1020AL & $9.52 \pm 0.20$ & $13.02 \pm 0.02$ & $2.01 \pm 0.02$ & $0.24 \pm 0.01$ \\
GUR1050AL & $9.44 \pm 0.42$ & $12.75 \pm 0.04$ & $2.13 \pm 0.01$ & $0.24 \pm 0.01$ \\
\hline
\end{tabular}

\subsubsection{Surface Roughness}

Figure 3 shows examples of various specimens photographed via 3DLSM at 1000× magnification. The images display a surface measuring $64,000 \mu \mathrm{m}^{2}$.

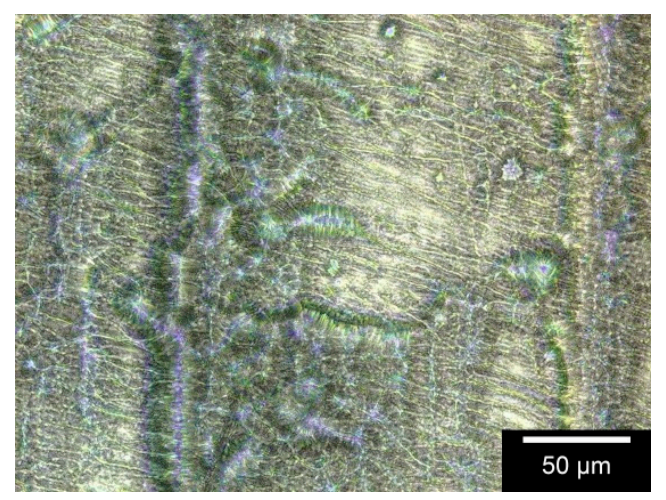

(a)

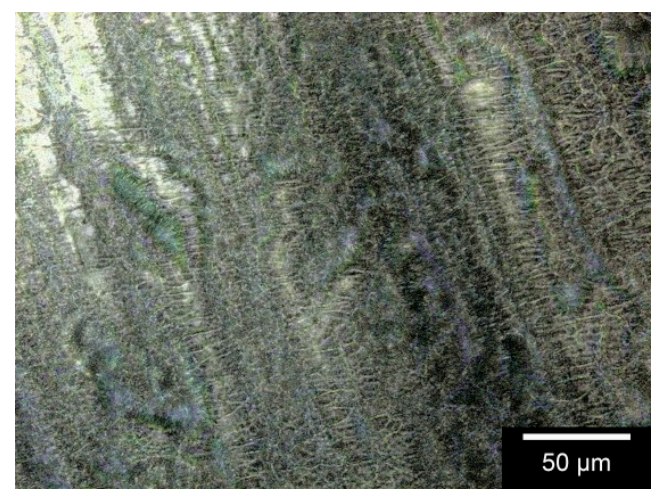

(c)

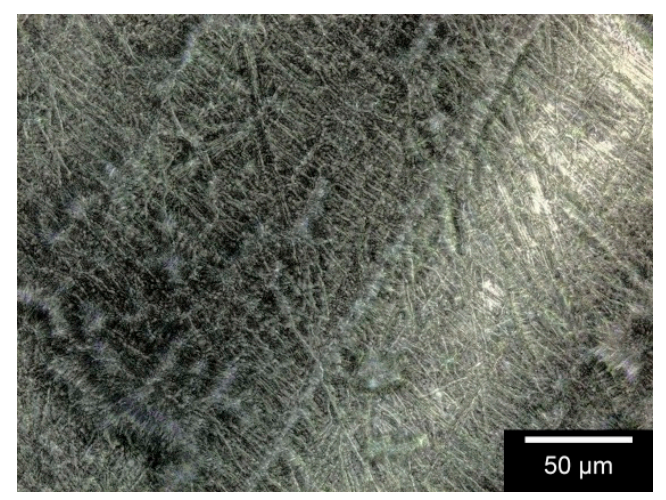

(b)

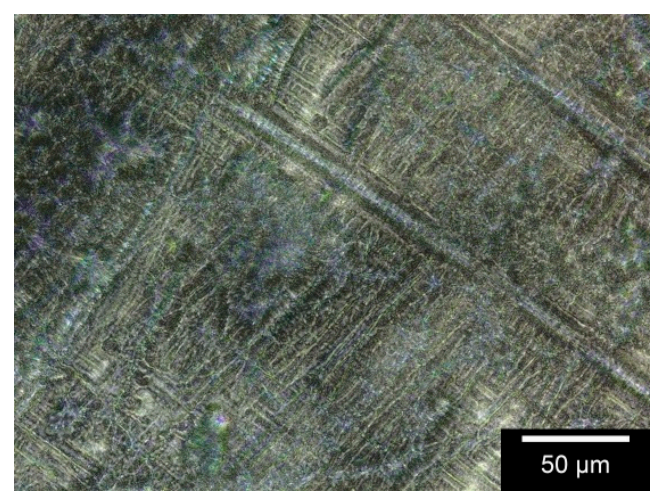

(d)

Figure 3. Surface roughness of specimens photographed with a Keyence 3DLSM VK-X210; 1000× magnification: A: GUR1020; B: GUR1050; C: GUR1020AL; D: GUR1050AL.

A significant difference $(\mathrm{p}<0.05)$ in the arithmetical mean height $\mathrm{S}_{\mathrm{a}}$ between GUR1020 and GUR1020AL has been observed (cf. Table 3). The $S_{a}$ of GUR1050 revealed no significant difference to that of GUR1050AL and neither did GUR1020 and GUR1050 significantly differ in their $\mathrm{S}_{\mathrm{a}}$.

Table 3. Overview of the arithmetical mean height $\left(\mathrm{S}_{\mathrm{a}}\right)$ of specimens $(\mathrm{N}=10)$.

\begin{tabular}{ccccc}
\hline Specimens & GUR1020 & GUR1050 & GUR1020AL & GUR1050AL \\
\hline$S_{\mathbf{a}}[\mu \mathrm{m}]$ & $2.02 \pm 0.43$ & $2.26 \pm 0.38$ & $2.57 \pm 0.48$ & $2.18 \pm 0.27$ \\
\hline
\end{tabular}




\subsubsection{Tensile Tests}

To discover the influence of admixing alendronate on composite stability of the various UHMWPEs, tensile tests were carried out. The stress-strain curves of the tested specimens are shown in Figure 4. The elongation-at-break data reveal various values depending on the GUR: GUR1050 $71-121 \%$ and GUR1020 150-174\%. The tensile modulus exhibited similar behavior-it delivered values ranging from 771 to $848 \mathrm{MPa}$ for GUR1050, and between 647 and $728 \mathrm{MPa}$ for GUR1020. The fracture stress of all the tested specimens fell within a similar range: 34-37 MPa (see Table 4 and Figure 5).

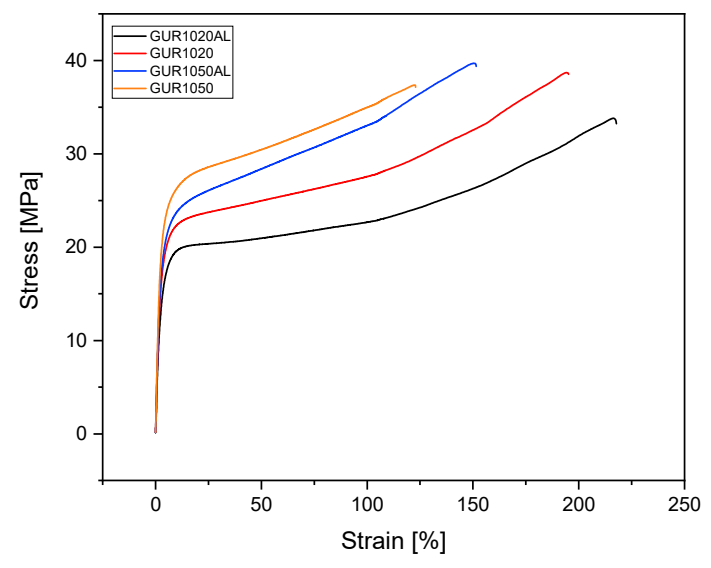

(a)

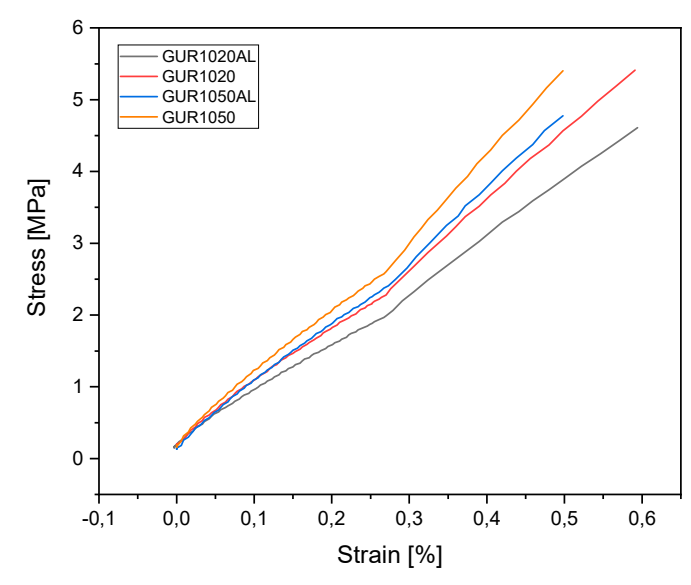

(b)

Figure 4. Stress-strain curves (a) GUR specimens; (b) the initial differences are magnified to facilitate comprehension.

Table 4. Tensile test results $(\mathrm{N}=6)$.

\begin{tabular}{lccc}
\hline \multicolumn{1}{c}{ Specimen } & $\mathrm{E}_{\mathrm{t}}[\mathrm{MPa}]$ & $\boldsymbol{\varepsilon t}_{\mathrm{B}}[\%]$ & $\sigma_{\mathrm{B}}[\mathrm{MPa}]$ \\
\hline GUR1050 & $821 \pm 30$ & $71 \pm 5$ & $36 \pm 10$ \\
GUR1050AL & $650 \pm 70$ & $122 \pm 116$ & $38 \pm 2$ \\
GUR1020 & $691 \pm 27$ & $151 \pm 3$ & $37 \pm 1$ \\
GUR1020AL & $635 \pm 15$ & $174 \pm 7$ & $34 \pm 1$ \\
\hline
\end{tabular}

$\mathrm{E}_{\mathrm{t}}$-Tensile modulus; $\varepsilon \mathrm{t}_{\mathrm{B}}$-nominal elongation at break; $\sigma_{\mathrm{B}}$-fracture stress.

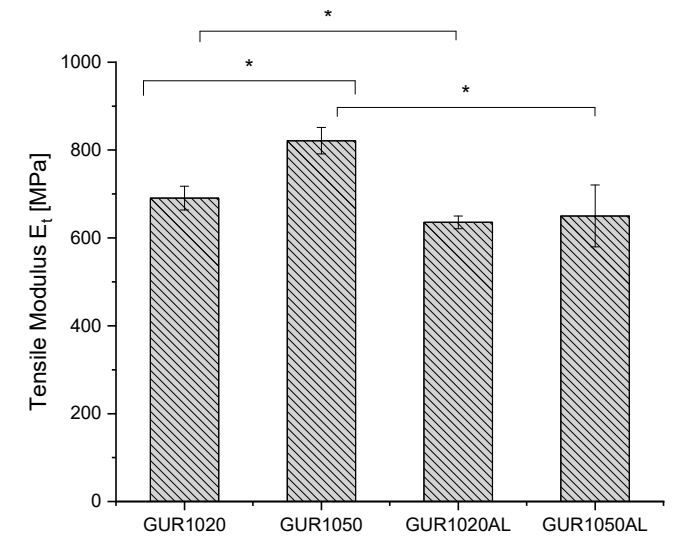

Figure 5. Tensile moduli comparison for various ultra-high molecular weight polyethylene (UHMWPEs), $\left.{ }^{*}\right) \mathrm{p}<0.05$. Measurements taken with a Zwick Z005 universal testing machine in accordance with DIN EN ISO 527, $\mathrm{N}=6$. 
After adding AL, the tensile modules of GUR1020 decreased to $92.1 \%$ and that of GUR1050 to $79.1 \%$. The elongation-at-break after adding AL increased in GUR1020 by $22.9 \%$ and in GUR1050 by $50.7 \%$. Fracture stress fell by $6.7 \%$ in GUR1020 and rose in GUR1050 by 3.5\%.

\subsubsection{DSC}

The enthalpy of fusion of the samples was determined by means of DSC (see Table 5) in order to determine the crystallinity. The crystallinity of GUR1020 was $52.47 \pm 2.41 \%$ and that of GUR1050 was $57.56 \pm 2.47 \%$. No significant difference was observed between the two values ( $p>0.05)$. The addition of AL changed the crystallinity of GUR1020 to $56.23 \pm 2.06 \%$ and that of GUR1050 to $55.20 \pm 3.46 \%$; neither change was significant at $\mathrm{p}>0.05$.

Table 5. Crystallinity percents measured by DSC; $\mathrm{N}=4$.

\begin{tabular}{lc}
\multicolumn{1}{c}{ Sample } & \% Crystallinity \\
\hline GUR1020 & $52.5 \pm 2.4$ \\
GUR1020AL & $56.2 \pm 2.1$ \\
GUR1050 & $57.6 \pm 2.5$ \\
GUR1050AL & $55.2 \pm 3.5$ \\
\hline
\end{tabular}

\subsection{Release Experiments}

The complex AL-OPA was well determined by HPLC. Compared to the pure OPA peak, the peak of the complex with a peak height over $4000 \mathrm{mV}$ was significantly higher than the pure OPA at $0.1 \mathrm{mV}$. The complex revealed a retention time of $5.73 \pm 0.13 \mathrm{~min}$ (see Figure 6) for which there were no peaks in the OPA spectrum.

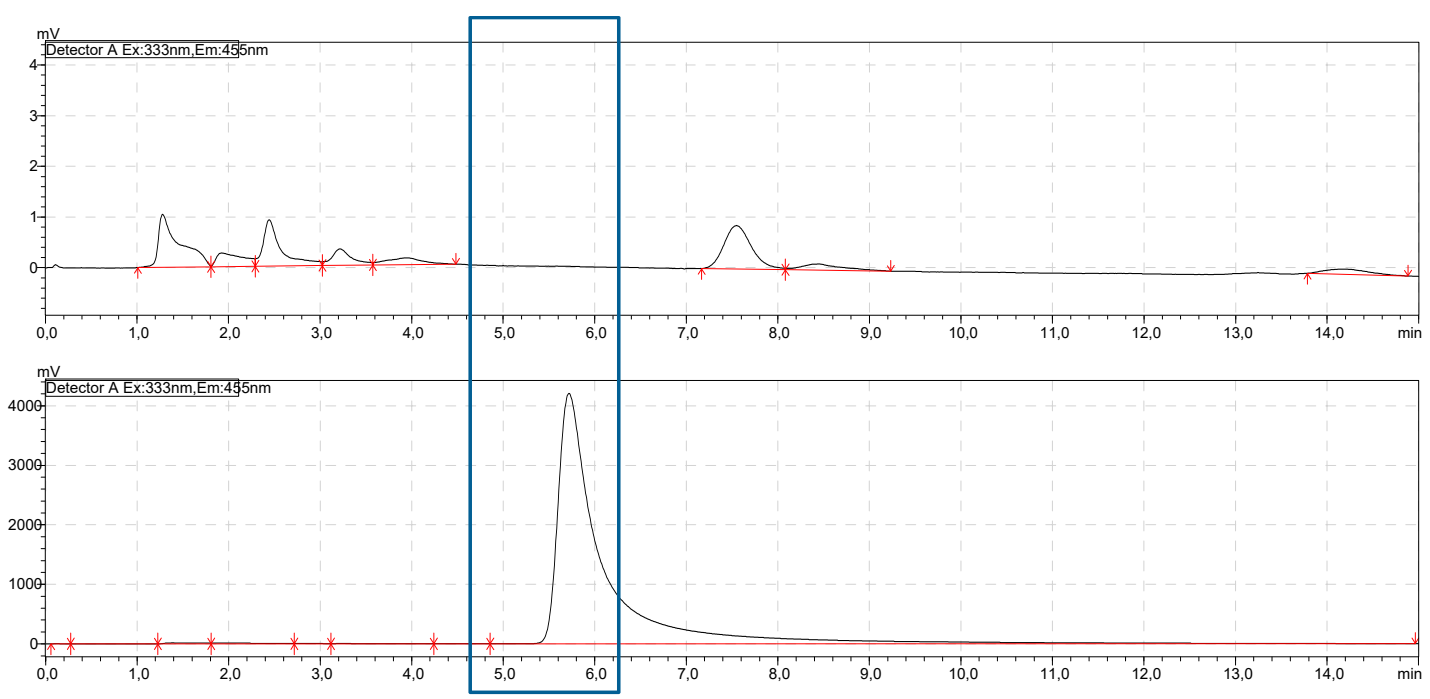

Figure 6. Chromatogram comparison of o-Phtadialdehyde (OPA) (above) and alendronate (AL)-OPA (below). Fluorescence detector: $333 \mathrm{~nm}$ excitation and $455 \mathrm{~nm}$ emission.

The calibration revealed a determination coefficient of $99.63 \%$, which resulted in a detection limit of $0.62 \mu \mathrm{g} / \mathrm{mL}$ and quantification limit of $1.88 \mu \mathrm{g} / \mathrm{mL}$ according to ICH [20].

The greatest AL release after $24 \mathrm{~h}$ is apparent at the beginning: $8.96 \pm 1.51 \mathrm{~g} / \mathrm{mL}$ for GUR1020 and $1.62 \pm 0.36 \mu \mathrm{g} / \mathrm{mL}$ for GUR1050 (see Figure 7). After 14 days, $0.34 \pm 0.21 \mu \mathrm{g} / \mathrm{mL}$ of AL was released from GUR1020, and $0.17 \pm 0.08 \mu \mathrm{g} / \mathrm{mL}$ from GUR1050. 


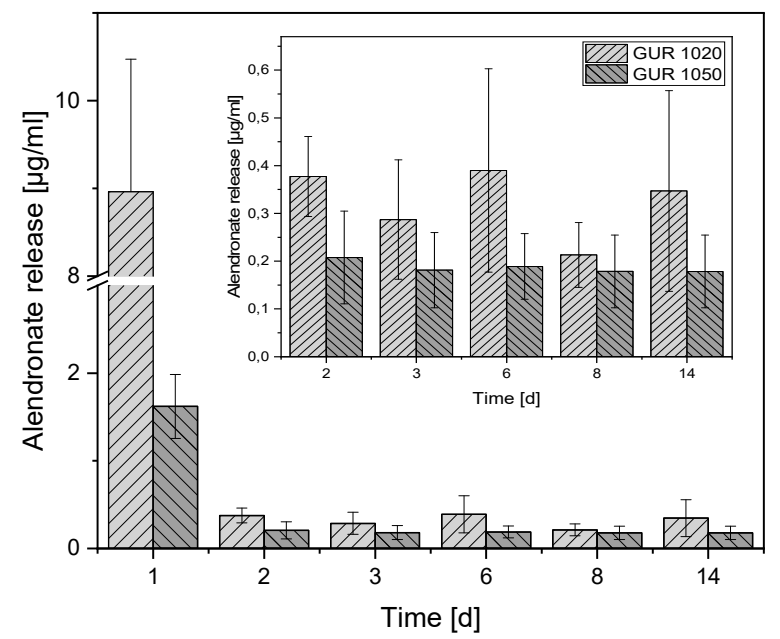

Figure 7. AL release overview; the smaller diagram is an enlargement of our day $2-14$ findings to facilitate comparison $[\mathrm{N}=30]$.

If one considers the cumulative release, it becomes clear that GUR1020 shows a release approx. four times as high as the GUR1050 in relation to the loading quantity. In addition, the release is almost linear from day 3 and has not been completed after 14 days (cf. Figure 8). In both cases, GUR1050's $0.1 \%$ and GUR 1020 's $0.45 \%$ after 14 days indicate a very low proportion of AL was released compared to their initial weight at manufacture.

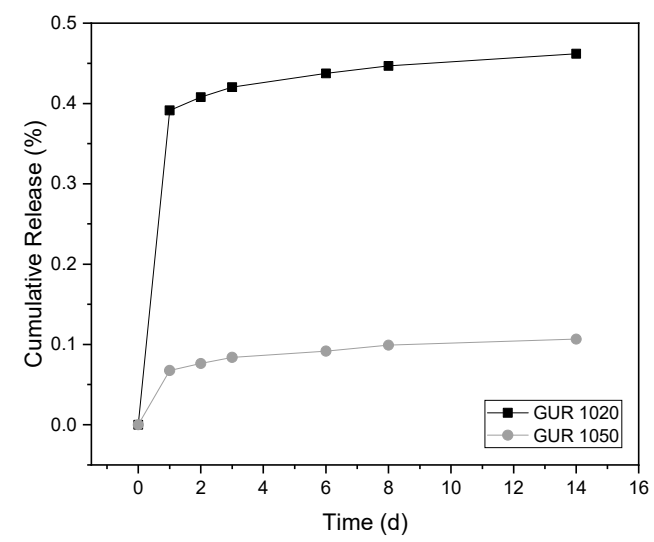

Figure 8. Cumulative AL release depending on the GUR used.

\subsection{Biocompatibility}

\subsubsection{Live/Dead Assay}

The live/dead assay (Table 6 and Figure 9) demonstrated well the increase in cell numbers over time. GUR1050AL exhibited higher cell counts than GUR1020AL. It was also be observed that the cell counts of GUR1020AL were significantly lower than those of pure GUR1020. On the other hand, GUR1050AL did not display such a strong reduction in cell counts compared to GUR1050. 
Table 6. Overview of GUR specimen cell counts [ $\mathrm{N}=10]$.

\begin{tabular}{lcccccc}
\hline & Time & \multicolumn{6}{c}{ cells per $\mathbf{~ m m}^{2}$} \\
\cline { 2 - 7 } Specime & \multicolumn{2}{c}{$\mathbf{2 4} \mathbf{~}$} & \multicolumn{2}{c}{$\mathbf{4 8} \mathbf{~ h}$} & \multicolumn{2}{c}{$\mathbf{7 2} \mathbf{~}$} \\
\cline { 2 - 7 } & live & dead & live & dead & live & dead \\
\hline GUR1020 & $56 \pm 16$ & $6 \pm 5$ & $70 \pm 16$ & $28 \pm 36$ & $123 \pm 19$ & $10 \pm 9$ \\
GUR1020AL & $17 \pm 14$ & $3 \pm 1$ & $45 \pm 20$ & $7 \pm 4$ & $30 \pm 19$ & $2 \pm 1$ \\
GUR1050 & $81 \pm 43$ & $6 \pm 3$ & $126 \pm 153$ & $4 \pm 4$ & $63 \pm 105$ & $6 \pm 2$ \\
GUT1050AL & $78 \pm 22$ & $50 \pm 66$ & $136 \pm 65$ & $8 \pm 10$ & $143 \pm 96$ & $3 \pm 2$ \\
\hline
\end{tabular}

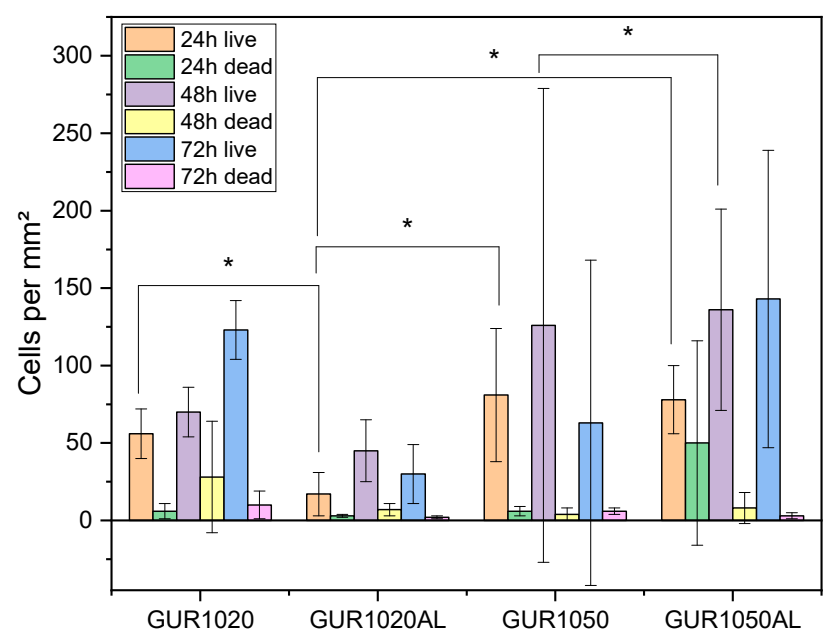

Figure 9. Overview of cells per $\mathrm{mm}^{2}$ in conjunction with various materials, *significant difference $\mathrm{p}<0.05, \mathrm{~N}=15$.

\subsubsection{Cell Proliferation (WST)}

The WST test revealed after 10 days that the cells on all specimens proliferated. Proliferation was, however, not as high as that on Thermanox ${ }^{\mathrm{TM}}$ membranes (Nunc, Rochester, USA), which served as our controls. Nevertheless, an increase in proliferation over time was documented. The increases that GUR1050 and GUR1050 demonstrated were highest compared to GUR1020 (see Figure 10).

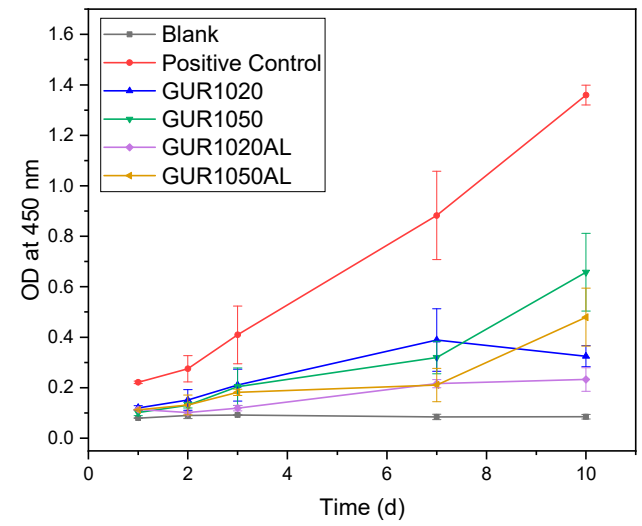

Figure 10. WST test overview, $\mathrm{N}=15$.

\subsection{3. $\mathrm{LDH}$}

LDH revealed no cytotoxicity in the specimens (Figure 11); all values fell within the negative-control range. 


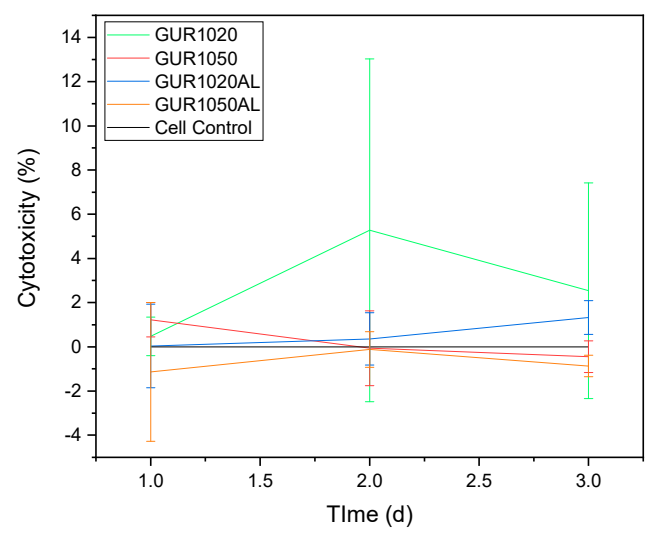

Figure 11. LDH test overview normalized to cell control, $\mathrm{N}=15$.

\section{Discussion}

\subsection{Characterization of the Different GUR Types and the Molds}

\subsubsection{Particle Size Distribution}

The GUR particles used by Kumar et al. [21] had a mean particle size of $90 \pm 30 \mu \mathrm{m}$. Greer et al. [22] unfortunately did not provide any information on the particle size of the GUR used. Gong et al. [15] used a GUR with a mean particle size of $150 \mu \mathrm{m}$. The particles we used had a much wider size range. The average particle size for GUR1020 was $54.3 \pm 52.5 \mu \mathrm{m}$ and for GUR1050 was $36.9 \pm 38.3 \mu \mathrm{m}$. Compared to these values $[15,21,22]$, the GUR types we used for this project showed a significantly smaller particle size.

\subsubsection{Surface Roughness}

The surface roughness of specimens can affect cell growth [23]. We found no significant difference in surface roughness $\left(\mathrm{S}_{\mathrm{a}}\right)$ among the specimens. It is the manufacturing process, which was identical in all our samples, that exerts the strongest influence on surface roughness. A change in this value due to the addition of alendronate can therefore be ruled out.

\subsubsection{Tensile Testing}

We noted a significant difference in elongation-at-break, in the tensile modules, and in fracture stress among the various GUR types. The findings of Greer at al. [22] were similar. However, they investigated the influence of radiation on crosslinking in UHMWPE. Their elongation-at-break values from native unirradiated specimens were at $396 \pm 20 \%$ for GUR1020 and $376 \pm 52 \%$ for GUR1050, much higher than the values we measured. This may be attributable to the difference in manufacturing processes-in this paper, the pressing of UHMWPE+AL having been performed at $140{ }^{\circ} \mathrm{C}$ rather than extrusion like Greer et al. [22]. An influence of AL on the mechanical parameters was documented: GUR1020's tensile module and fracture stress decreased due to the addition of AL. With GUR1050, adding $0.5 \mathrm{wt} \%$ AL revealed that the tensile module was also reduced, but fracture stress increased. This factor can be attributed to the reduction in crystallinity. James et al. [17] report a similar relationship between UHMWPE and hyaluronic acid. Crystallinity fell from $52.79 \pm 0.08 \%$ through the addition of hyaluronic acid to $47.14 \pm 0.04 \%$. Comparable values for the tensile moduli for alendronate-containing UHMWPE were also determined by Gong et al. [15], which have dealt with the mechanical and tribological behavior of UHMWPE + AL after mechanical loading. They, however, did not draw comparisons with unloaded UHMWPE. The addition of $0.5 \mathrm{wt} \%$ alendronate increased the elongation at break for GUR1020 by $23 \%$ and for GUR1050 by $49 \%$. This could be explained by a decreasing crystallinity. 


\subsubsection{DSC}

The DSC investigations revealed no significant change in crystallinity. There was, however, a slight difference that could have had an influence on release and mechanical characteristics. In the findings of James et al. [17], who investigated changes in UHMWPE crystallinity, the latter was reduced by the addition of hyaluronic acid, but they do not mention whether those changes were significant. We observed that the crystallinity of GUR1020 and GUR1050 lies within the same range of values as reported by Hofmann et al. [24], who investigated the crystallinity of various UHMWPEs. They reported UHMWPE crystallinity values of $2.7 \times 10^{6} \mathrm{~g} / \mathrm{mol}$ of $60 \%$ and for UHMWPE with $1.5 \times 10^{6} \mathrm{~g} / \mathrm{mol}$ of $62 \%$. Our crystallinity values lie slightly lower: GUR1020 52.5\% and GUR1050 57.6\%; however, the UHMWPEs used for this work had higher molar masses: GUR1020 $3.5 \times 10^{6} \mathrm{~g} / \mathrm{mol}$, and GUR1050 $5.5 \times 10^{6} \mathrm{~g} / \mathrm{mol}$

\subsection{Release Experiments}

The alendronate can only be found on the surfaces of the various GUR particles, which are then pressed further in the course of the process. Depending on the mean diameter $\left(\mathrm{d}_{1020}=54.3 \pm 52.5 \mu \mathrm{m}\right.$; $\left.\mathrm{d}_{1050}=36.9 \pm 38.3 \mu \mathrm{m}\right)$ of the particles, the surface area of the GUR1020 particles $\left(\mathrm{a}_{1020}=9263 \mu \mathrm{m}^{3}\right)$ is almost twice as large as that of the GUR1050 particles $\left(\mathrm{a}_{1050}=4278 \mu \mathrm{m}^{3}\right)$. The particle size distribution shows a significantly higher value for all other size classes with the GUR1020, except for the very small particles of 0.1-10 $\mu \mathrm{m}$ which predominate with GUR1050 (see Table 1). This effectively increases the surface area of the particles and thus the AL loading, which can explain the much higher AL release from GUR1020. Considering that there is no diffusion in the GUR, except the marginal areas, one comes to the same conclusion. Oral et al. [25] showed similar results, where the question was reversed and vitamin E should diffuse into the GUR. But they also show that a 1-mm deep penetration without special measures can be assumed. The same should then apply to the release as well. This would also explain the relatively minor amount of released alendronate. In contrast to Manoj Kumar et al. [21], the active ingredient was added to the GUR before the moldings were pressed and not impregnated on the surface after the moldings had been fabricated, and they applied gentamycin rather than AL. Their impregnation procedure as well as the different substances used are the reasons for the very pronounced release behavior differences: our $0.5 \%$ as opposed to $90 \%$ by Manoj Kumar et al. [21]). $\mathrm{Qu}$ et al. [16] describe a similar method to produce UHMWPE but at a much higher temperature. Moreover, both Qu et. al [16] and Liu et al. [14] reported wear particles from molds made of UHMWPE with AL that displayed significantly larger surface area than our molds. The larger surface of the wear particles led to a much greater release of AL $[14,16]$. However, it became clear that the release depends very much on the particle size of the UHMWPE used: GUR1020 released four times as much AL as did GUR1050 despite the fact that both specimens had undergone the same production method and were subject to the same release conditions. A comparative description of the release behavior of different UHMWPE as a function of particle size has not yet been described in the literature.

\subsection{Biocompatibility}

\subsubsection{Live/Dead Assay}

In the live/dead assay, GUR1050 exhibited much higher cell counts than GUR1020. This is because GUR1020 exhibited greater amounts of AL release and, in line with Im et al. [26], concentrations exceeding $10^{-4} \mathrm{M}$, leading to a decrease in cell proliferation. However, it was also the case that with decreasing released AL concentrations, an increase in the cell count was observed, similar to what has already been described by Guiliani et al. [27] and Im et al. [26]. Guiliani et al. [27] reported on AL concentrations ranging from $10^{-8}$ to $10^{-13} \mathrm{~mol} / \mathrm{L}$ and of etidronate concentrations between $10^{-7}$ and $10^{-9} \mathrm{~mol} / \mathrm{L}$. Im et al. [26] described AL concentrations in the $10^{-7}$ to $10^{-12}$ range; the lowest concentration's effect on proliferation was rather weak. These results were also observed in all live/dead experiments. 


\subsubsection{WST}

In their investigations, $\mathrm{Qu}$ et al. [16] und Liu et. al [14] tested the biocompatibility of AL-loaded UHMWPE by using the MTT test instead of the WST test. Their results resembled ours. We observed, exactly as Xiong et al. [28] did, that cell counts rose in relation to AL concentration. In addition, a slight inhibition of proliferation was observed at the beginning, as already described by Reinholz et al. [29], who dealt with the regulation of cell proliferation, differentiation and gene expression of human osteoblasts by bisphosphonates. However, they employed the bisphosphonates etidronate, pamidronate, and zolendronate in their investigations.

\subsection{3. $\mathrm{LDH}$}

The results from the cytotoxicity assay very slightly exceeded those from our negative controls (cells only). Compared to the wear particle findings of Liu et al. [14], our results (with values of $2 \%$ for cytoxicity) also lie within the same range as the controls. Liu et al. studied the in vitro release and cellular response of AL-loaded UHMWPE wear particles. Their controls revealed a $2 \%$ cytotoxicity value and a range of 5 to $7 \%$ for wear particles containing AL. Thus, our values were clearly below their values for the controls. It was thus possible to prove that no cell toxicity was present at all.

\section{Conclusions}

In the present work, it has been proved that the selection of the UHMWPE has an influence on the release of AL. The particle size of the GUR in particular has a strong influence on release behavior. The way in which the UHMWPE/AL blends are produced, e.g., by pressing instead of extrusion, or the temperature control during pressing at $140{ }^{\circ} \mathrm{C}$ instead of $180{ }^{\circ} \mathrm{C}$ also influences the release of AL. In addition, an influence of the concentration of alendronate on cell proliferation, as described in the literature [26-28], was demonstrated. An AL concentration over $10^{4} \mathrm{M}$ resulted in inhibited proliferation, whereas a falling AL concentration correlated with a rise in cell counts.

Author Contributions: H.O.M., M.S., B.S., C.F. and A.B. and conceived and designed the experiments; U.M. made the moldings, J.W., M.S. and S.L., performed the experiments; M.S., C.F. and J.W. analyzed the data; A.B. and H.O.M. contributed reagents/materials/analysis tools; M.S. and J.W. wrote the paper. All authors critically reviewed the content and approved final version for publication.

Funding: This research received no external funding. The APC was funded by the German Research Foundation (DFG) and the University of Freiburg in the funding program Open Access Publishing.

Conflicts of Interest: The authors state that they have no conflict of interest to declare.

\section{References}

1. Destatis. Gesundheit-Fallpauschalenbezogene krankenhausstatistik (Drg-Statistik) Operationen UND prozeduren Der Vollstationären Patientinnen UND Patienten in Krankenhäusern (4-Steller); Statistisches Bundesamt (Destatis): Wiesbadem, Germany, 2016; p. 72.

2. Bleß, H.H.; Kip, M. Weißbuch Gelenkersatz-Versorgungssituation Endoprothetischer Hüft-UND Knieoperationen in Deutschland; Springer: Berlin/Heidelberg, Germany, 2017; p. XII, 142.

3. Krause, A.; Kirschning, A.; Drager, G. Bioorthogonal metal-free click-ligation of crgd-pentapeptide to alginate. Org. Biomol. Chem. 2012, 10, 5547-5553. [CrossRef] [PubMed]

4. Harris, W.H. Conquest of a worldwide human disease: Particle-induced periprosthetic osteolysis. Clin. Orthop. Relat. Res. 2004, 429, 39-42. [CrossRef]

5. Krause, A.; Schonau, E.; Gollhofer, A.; Duran, I.; Ferrari-Malik, A.; Freyler, K.; Ritzmann, R. Alleviation of motor impairments in patients with cerebral palsy: Acute effects of whole-body vibration on stretch reflex response, voluntary muscle activation and mobility. Front. Neurol. 2017, 8, 416. [CrossRef] [PubMed]

6. Childs, L.M.; Goater, J.J.; O'Keefe, R.J.; Schwarz, E.M. Efficacy of etanercept for wear debris-induced osteolysis. J. Bone Miner. Res. 2001, 16, 338-347. [CrossRef] [PubMed] 
7. Millett, P.J.; Allen, M.J.; Bostrom, M.P.G. Effects of alendronate on particle-induced osteolysis in a rat model. J. Bone Jt. Surg. 2002, 84, 236-249. [CrossRef]

8. Zhu, F.-B.; Cai, X.Z.; Yan, S.-G.; Zhu, H.-X.; Li, R. The effects of local and systemic alendronate delivery on wear debris-induced osteolysis in vivo. J. Orth. Res. 2010, 28, 893-899. [CrossRef]

9. Wu, H.; Zheng, O.; Du, J.; Yan, Y.; Liu, C. A new drug delivery system-ciprofloxacine/tricalcium phosphate delivery capsule (ctdc) and its in vitro drug release pattern. J. Tongji Med. Univ. 1997, 17, 160-164.

10. Olszynski, W.P.; Davison, K.S. Alendronate for the treatment of osteoporosis in men. Expert Opin. Pharmacother. 2008, 9, 491-498. [CrossRef]

11. Sharpe, M.; Noble, S.; Spencer, C.M. Alendronate: An update of its use in osteoporosis. Drugs 2001, 61, 999-1039. [CrossRef]

12. Kurtz, S.M. Chapter 4-The Origins of uhmwpe in total hip arthroplasty. In The Uhmwpe Handbook; Kurtz, S.M., Ed.; Academic Press: San Diego, CA, USA, 2004; pp. 53-70.

13. Kurtz, S.M. Chapter 2-From ethylene gas to uhmwpe component: The process of producing orthopedic implants. In Uhmwpe Biomaterials Handbook, 2nd ed.; Kurtz, S.M., Ed.; Academic Press: Boston, MA, USA, 2009; pp. 7-19.

14. Liu, Y.; Shi, F.; Gong, K.; Liu, Y.; Zhi, W.; Weng, J.; Qu, S. Study on critical-sized ultra-high molecular weight polyethylene wear particles loaded with alendronate sodium: In vitro release and cell response. J. Mater. Sci. Mater. Med. 2017, 28, 56. [CrossRef]

15. Gong, K.; Qu, S.; Liu, Y.; Wang, J.; Zhang, Y.; Jiang, C.; Shen, R. The mechanical and tribological properties of uhmwpe loaded aln after mechanical activation for joint replacements. J. Mech. Behav. Biomed. Mater. 2016, 61,334-344. [CrossRef] [PubMed]

16. Qu, S.; Bai, Y.; Liu, X.; Fu, R.; Duan, K.; Weng, J. Study on in vitro release and cell response to alendronate sodium-loaded ultrahigh molecular weight polyethylene loaded with alendronate sodium wear particles to treat the particles-induced osteolysis. J. Biomed. Mater. Res. A 2013, 101, 394-403. [CrossRef] [PubMed]

17. James, S.P.; Oldinski, R.; Zhang, M.; Schwartz, H. Chapter 18-uhmwpe/hyaluronan microcomposite biomaterials. In Uhmwpe Biomaterials Handbook, 2nd ed.; Kurtz, S.M., Ed.; Academic Press: Boston, MA, USA, 2009; pp. 259-276.

18. Rauscher, K.; Vogt, J.; Wilke, I.; Friebe, R. Chemische Tabellen UND Rechentafeln Für Die Analytische Praxis; Verlag Harri Deutsch: Frankfurt/Main, Germany, 2000.

19. Al Deeb, S.K.; Hamdan, I.I.; Al Najjar, S.M. Spectroscopic and hplc methods for the determination of alendronate in tablets and urine. Talanta 2004, 64, 695-702. [CrossRef] [PubMed]

20. Validation of analytical procedures: Text and methodology q2(r1). In Proceedings of the International Conference On Harmonisation Of Technical Requirements For Registration Of Pharmaceuticals For Human Use I, Geneva, Switzerland, 6 November 1996.

21. Manoj Kumar, R.; Gupta, P.; Sharma, S.K.; Mittal, A.; Shekhar, M.; Kumar, V.; Manoj Kumar, B.V.; Roy, P.; Lahiri, D. Sustained drug release from surface modified uhmwpe for acetabular cup lining in total hip implant. Mater. Sci. Eng. C 2017, 77, 649-661. [CrossRef] [PubMed]

22. Greer, K.; King, R.; Chan, F. The effects of raw material, irradiation dose, and irradiation source on crosslinking of uhmwpe. J. ASTM Int. 2004, 1, 1-11. [CrossRef]

23. Martin, J.Y.; Schwartz, Z.; Hummert, T.W.; Schraub, D.M.; Simpson, J.; Lankford, J.; Dean, D.D.; Cochran, D.L.; Boyan, B.D. Effect of titanium surface roughness on proliferation, differentiation, and protein synthesis of human osteoblast-like cells (mg63). J. Biomed. Mater. Res. 1995, 29, 389-401. [CrossRef] [PubMed]

24. Hofmann, D.; Schulz, E.; Fanter, D.; Fuhrmann, H.; Bilda, D. Crystallinity and lateral crystallite size of different uhmw pe materials. J. Appl. Polym. Sci. 1991, 42, 863-866. [CrossRef]

25. Oral, E.; Wannomae, K.K.; Rowell, S.L.; Muratoglu, O.K. Diffusion of vitamin e in ultra-high molecular weight polyethylene. Biomaterials 2007, 28, 5225-5237. [CrossRef]

26. Im, G.I.; Qureshi, S.A.; Kenney, J.; Rubash, H.E.; Shanbhag, A.S. Osteoblast proliferation and maturation by bisphosphonates. Biomaterials 2004, 25, 4105-4115. [CrossRef]

27. Giuliani, N.; Pedrazzoni, M.; Negri, G.; Passeri, G.; Impicciatore, M.; Girasole, G. Bisphosphonates stimulate formation of osteoblast precursors and mineralized nodules in murine and human bone marrow cultures in vitro and promote early osteoblastogenesis in young and aged mice in vivo. Bone 1998, 22, 455-461. [CrossRef] 
28. Xiong, Y.; Yang, H.; Feng, J.; Shi, Z.; Wu, L. Effects of alendronate on the proliferation and osteogenic differentiation of mg-63 cells. J. Int. Med. Res. 2009, 37, 407-416. [CrossRef] [PubMed]

29. Reinholz, G.G.; Getz, B.; Pederson, L.; Sanders, E.S.; Subramaniam, M.; Ingle, J.N.; Spelsberg, T.C. Bisphosphonates directly regulate cell proliferation, differentiation, and gene expression in human osteoblasts. Cancer Res. 2000, 60, 6001-6007. [PubMed] 